\title{
EXTRAVERSION PERSONALITY AS A MODERATOR ON THE RELATIONSHIP OF EMOTIONAL INTELLIGENCE AND SELF-ESTEEM OF EMPLOYEES
}

\author{
Siti Sarawati Johar ${ }^{1}$ \\ ${ }^{1}$ Dr., Senior Lecturer, MALAYSIA, ssarrajoe@gmail.com
}

\begin{abstract}
Personality dimension has gained a place in the fundamental of psychological research. It was detected that, personality can give influence on the employee behaviour in the workplace. The theoretical solutions are simply not able to unlock the psychological issues because it is closely linked to affective, cognitive and human behaviour in the workplace. In this study, the issues in the workplace are referring to personality, emotional intelligence and self-esteem of employees. The specific purpose of this study was to test the effect of extraversion personality as a moderator towards the relationship of emotional intelligence and self-esteem of employees. A total of 196 civil servants in the Local Authority (LA) have been selected as respondents. Measurement tools that used is Eysenck Personality Questionnaire-Revised Short Form (EPQR-S), Emotional Intelligence Self-Description Inventory (EISDI), and Rosenberg Self-Esteem Scale (RSES). The data was analysed by using the hierarchical regression analysis. The finding shows that the two hypotheses are accepted. From this analysis as well, there was a moderating effect of extraversion personality on the relationship between emotional intelligence (perception and appraisal of emotion, and understanding emotions) with self-esteem of employees. The most important finding shows that extraversion personality serves as moderator when the relationship between emotional intelligence and self-esteem are enhanced if extraversion were on a high level. This is compared with the low levels of extraversion personality that causing on relationship of emotional intelligence with self-esteem becoming weaker.
\end{abstract}

Keywords: Extraversion, personality, moderator, emotional intelligence, self-esteem;

\section{INTRODUCTION}

The public sector is one of the dimensions in a very significant factor entities supporting role in human capital development of a country. It is an administrative and management machinery that allows people to bring the country's development framework is worth and meaning in the world rankings as a flexible model. It is to remain as the country that provided the services which include the services by statutory and non-statutory bodies, local authorities (PBT), district offices and state government agencies as well as various categories of posts in each ministry. Although clearly a transformation agenda and a plan has been formulated and applied to nationals of the public sector in local authorities in this country, especially in the era of the 21 st century, but local authorities still cannot be separated from issues and challenges that exist from within the organization or from outside. Accordingly, this study focuses specifically on organizational psychology scenario of civil servants, by testing the effects of emotional intelligence on the self-esteem of employees in 
the public sector. However, there is likely moderator factor that also influence the emotional intelligence and self-esteem of employees in the workplace through the role of personality factor among them.

\section{RESEARCH BACKGROUND}

This research focused on civil servants working in local authorities in Malaysia. They have a high frequency communicate with the community which is interact with services provided are directly and indirectly. Despite various policies, systems and transformative introduced and implemented from time to time for all public servants in achieving quality of work, but there is still a vacuum here and there until tarnish the image of the public sector. The public sector is found often face pressure from society to function more proactively improve performance and service delivery systems, including the role of local authorities (Ibrahim and Abdul Karim, 2004). According to Datuk Seri Abu Bakar Abdullah said in a statement on 21 November 2010 at the Putrajaya International Convention Centre, which states that by 6133 the government employees have reported problems in the discipline and poor performance in 2009, which in turn has increased by 789 cases compared with 2008 (Daily News, 2010). The increase makes people wonder how far public servants can change the bias (Zulnaidi, 2008) and transformed into a strength that could improve the image of the organization.

In summary, the focus of researchers doing in this study is to investigate the effect of emotional intelligence (perception and appraisal of emotion; and understanding emotions) on self-esteem was influenced by employee personality as a moderator impact factor. Thus on the basis of several existing well-established theory, this study was undertaken to observe the phenomenon of the public sector in this country that are appropriate to the current situation. Even the instruments and theories used is from the west, but the results of this study may be able to confirm that it can be adapted in this country and more consistent with the scenario of local people and local organizations. The function of personality trait as a moderator in research already tested by several researchers (Brian et al, 2009; Abdul Kadir, 2010; Othman et al, 2011; Sandeep and Singh, 2011; Bao and Chun, 2012). Therefore, these new findings in this research are clues to the study of personality trait and its impact on emotional intelligence and self-esteem employees.

\section{RESEARCH QUESTIONS}

Research question 1: Does the effect of extraversion personality moderate the relationship of emotional intelligence (perception and appraisal of emotion) and self-esteem of employees?

Research question 2: Does the effect of extraversion personality moderate the relationship between of emotional intelligence (understanding emotions) and self-esteem of employees?

\section{RESEARCH HYPOTHESIS}

Bao Chun (2012) in their study of 442 respondents in China have discovered the existence of extraversion trait as a moderator effect on the relationship between emotional intelligence with other variables such as conflict management. He found that personality trait of extraversion may indeed be a moderator in the study, although their study was to test the function of extraversion as a moderator in the relationship between emotional intelligence and other variables. Abdullah et al. (1998) also found that there is a significant positive correlation between extraversion trait with optimistic and pessimistic (the characteristics of self-esteem). Thus, it can be assumed that the trait extraversion has a relationship with emotional intelligence and selfesteem, but also assumed to function as a moderator between the two variables.

Based on the above discussion, the researchers have established the hypotheses like below:

$\mathbf{H}_{1}$ : There is an effect of extraversion personality as a moderator in the relationship of emotional intelligence (perception and appraisal of emotion) and self-esteem of employees.

$\mathbf{H}_{2:}$ There is an effect of extraversion personality as a moderator in the relationship of emotional intelligence (understanding emotions) and self-esteem of employees.

\section{METHODOLOGY}

\subsection{Research Design}

This study is a type of non-experimental study and it is also a form of field studies with the use of descriptive statistics and regression. Field studies are quite relevant for use in this study due to its high reliability while consumption was relatively low cost (Maimunah, 1992). Requirements of this study are too descriptive and hypothesis testing. Hypothesis testing also had the approach to the interpretation of the independent variables in two or more factors in certain conditions (Mclntyre, 2005). In this study, regression testing is 
describing the effect or impact of the relationship between variables.

\subsection{Research Location}

Site of this research selected as the study location are two body agencies Local Authority (LA) of the city council in the southern peninsular of Malaysia. In researcher knowledge, such a study has yet to be carried out by any party bound at the locations that have mentioned. The study focused on the state of the city council and this also means that the city hall, local municipalities, and local district councils are not included in a LA sample in this study.

\subsection{Subjects}

Sample of this study is focused only on employee category with a total of 403 employees and shows the proposed sample size was 196 people according to Schedule of Size Sample Determination (Krejcie and Morgan, 1970). This study respondents from two city councils in Malaysia where the category of employees is from group grade 22 until grade 44. This category selection is taken from several units and departments in both the city council. Possibility of sampling error is $5 \%$ for the sample size formula by Krejcie and Morgan (1970) was developed using $95 \%$ confidence interval is 0.05 . Systematic random sampling method used in the process of selecting a sample for this study.

\subsection{Research Instruments}

Questionnaire of Emotional Intelligence Self-Description Inventory (EISDI; Groves et al., 2006) is used in this study to measure emotional intelligence (perception and appraisal of emotion; and understanding emotions) of employees in the public sector. Instrument reliability is .915. While questionnaire of Eysenck Personality Questionnaire Revised-Short Form (EPQR-S; Eysenck et al., 1985) is to measure the extraversion personality of employees as a moderator, and reliability of the instrument used in this study was .734. Rosenberg Self-Esteem Scale (RSES; Rosenberg, 1965) is to measure the self-esteem of employees and reliability of the instrument used in this study was .794. Reliability three surveys have a relatively high value of reliability and can be trusted to use a good quality research results.

\section{RESEARCH RESULT}

\subsection{Hypothesis 1: There Is An Effect Of Extraversion Personality As A Moderator In The Relationship Between Emotional Intelligence (Perception And Appraisal Of Emotion) And Self-Esteem Of Employees.}

To test the significant effect of an extraversion personality as a moderator on the relationship between perception and appraisal of emotion with employee's self-esteem, a model of hierarchical regression analysis was conducted. The results for the base model is $R^{2}=.160, p<.05$, limited model $\left(R^{2}=.203, p<.05\right)$ and full model $\left(R^{2}=.225, p<.05\right)$. The results of this analysis showed the factor of perception and appraisal of emotion was contributed $16.0 \%$ to the variance of self-esteem (refer to the base model). When the perception and appraisal of emotion are included in the model, an additional factor of extraversion has increased the contribution factor of perception and appraisal of emotion to $20.3 \%$ (limited model).

Then, perception and appraisal of emotion with extraversion personality was included in the full model equations, there was found that perception and appraisal of emotion with extraversion personality contribute an additional $2.1 \%$ of variance on the relationship between perception and appraisal of emotion and selfesteem. Quite clearly, the $\left(R^{2}=.225, p=.039\right)$ for the full model is significant at the level of 0.05 , and the hypotheses of this study was accepted. This situation shows that the level of the personality trait of extraversion serves as a moderator in the relationship of perception and appraisal of emotion, with employee self-esteem.

Table 1.0: Moderator Effect on Relationship of Perception and appraisal of emotion with Self-Esteem

\begin{tabular}{|l|l|c|c|c|}
\hline \multirow{2}{*}{ MODEL } & \multicolumn{2}{|c|}{ EQUATION } & \multicolumn{3}{c|}{ SELF-ESTEEM } \\
\cline { 3 - 5 } & \multicolumn{1}{|c|}{$\mathrm{R}^{2}$} & $\Delta \mathrm{R}^{2}$ & $\Delta$ Sig $\mathrm{F}$ \\
\hline 1. Basic & Self-Esteem $=\mathrm{i}_{1}+\mathrm{b}_{1} \mathrm{X}+\mathrm{e}_{1}$ & $.160^{* \star}$ & $.160^{* \star}$ & .000 \\
\hline 2. Limited & Self-Esteem $=\mathrm{i}_{2}+\mathrm{b}_{2} \mathrm{X}+\mathrm{c}_{2} \mathrm{Z}+\mathrm{e}_{2}$ & $.203^{* *}$ & $.044^{* \star}$ & .004 \\
\hline 3. Full & Self-Esteem $=\mathrm{i}_{3}+\mathrm{b}_{3} \mathrm{X}_{3} \mathrm{Z}+\mathrm{c}+\mathrm{d}+\mathrm{e}_{3} \mathrm{XZ}{ }_{3}{ }_{3}$ & $.225^{* \star}$ & $.021^{* \star}$ & .039 \\
\hline
\end{tabular}

Note: ** significant at the level of $p<0.05, X=$ perception and emotion ratings, $Z=$ extraversion, ${ }^{*}$ the multiple perceptions and emotional assessment, and extraversion 
Perception and appraisal of emotion with self-esteem are categorized into two groups, high and low mean scores in extraversion. High group is set to a value exceeding the mean and lower group is set to a value less than the amount of mean. Table below shows the mean scores of perception and appraisal of emotion with self-esteem by category of extraversion.

Table 2.0: Mean Score Perception and Appraisal of Emotion on Self-Esteem Based To Low and High of Extraversion

\begin{tabular}{|c|c|c|c|}
\hline \multirow{2}{*}{ Variables } & \multicolumn{2}{c|}{ Perception and Emotional Assessment } \\
\cline { 2 - 4 } & Low & High \\
\hline \multirow{2}{*}{ Self-Esteem } & High & 2.045 & 2.104 \\
\cline { 2 - 4 } & Low & 0.126 & 0.388 \\
\hline
\end{tabular}

\subsection{Hypothesis 2: There Is An Effect Of Extraversion Personality As A Moderator In The Relationship Between Emotional Intelligence (Understanding Emotions) And Self-Esteem Of Employees.}

To test the significant effect of an extraversion personality as a moderator on the relationship between understanding emotions with self-esteem, a model of hierarchical regression analysis was conducted. The results for the base model is $R^{2}=.147, p<.05$, limited model $\left(R^{2}=.197, p<.05\right)$ and full model $\left(R^{2}=.231, p\right.$ $<.05$ ). The results of this analysis showed the factor of understanding emotions was contributed $14.7 \%$ to the variance of self-esteem (refer to the base model). When the understanding emotions are included in the model, an additional factor of extraversion has increased the contribution factor of understanding emotions to $19.7 \%$ (limited model).

Then, understanding emotions with extraversion personality was included in the full model equations, there was found that understanding emotions with extraversion personality contribute an additional $3.5 \%$ of variance on the relationship between understanding emotions and self-esteem. Next, the value $\left(R^{2}=.231, p=\right.$ .008 ) for the full model is significant at the level of 0.05 , and the hypotheses of this study was accepted. This situation shows that the level of the personality trait of extraversion serves as a moderator in the relationship of understanding emotions, with employee self-esteem.

Table 3.0: Moderator Effect on Relationship of Understanding Emotions with Self-Esteem

\begin{tabular}{|c|l|c|c|c|}
\hline \multirow{2}{*}{ Model } & \multicolumn{1}{|c|}{ Equation } & \multicolumn{3}{|c|}{ Self-Esteem } \\
\cline { 3 - 5 } & & $\mathrm{R}^{2}$ & $\Delta \mathrm{R}^{2}$ & $\Delta$ Sig $\mathrm{F}$ \\
\hline $1 . \quad$ Basic & Self-Esteem $=\mathrm{i}_{1}+\mathrm{b}_{1} \mathrm{X}+\mathrm{e}_{1}$ & $.147^{* *}$ & $.147^{* *}$ & .000 \\
\hline $2 . \quad$ Limited & Self-Esteem $=\mathrm{i}_{2}+\mathrm{b}_{2} \mathrm{X}+\mathrm{c}_{2} \mathrm{Z}+\mathrm{e}_{2}$ & $.197^{* *}$ & $.050^{* *}$ & .002 \\
\hline N. Full & $\begin{array}{l}\text { Self-Esteem }=\mathrm{i}_{3}+\mathrm{b}_{3} \mathrm{X}_{3} \mathrm{Z}+\mathrm{c}+\mathrm{d}+ \\
\mathrm{e}_{3} \mathrm{XZ}{ }^{*}{ }_{3}\end{array}$ & $.231^{* *}$ & $.035^{* *}$ & .008 \\
\hline Note: ${ }^{* *}$ significant at the level of $\mathrm{p}<0.05, \mathrm{X}=$ understanding emotions, $\mathrm{Z}=$ extraversion, ${ }^{*}$ the multiple unders
\end{tabular}
emotions, and extraversion

Understanding emotions with self-esteem are categorized into two groups, high and low mean scores in extraversion. High group is set to a value exceeding the mean and lower group is set to a value less than the amount of mean. Table below shows the mean scores of understanding emotions with self-esteem by category of extraversion.

Table 4.0: Mean Score Understanding Emotions on Self-Esteem Based to Low and High of Extraversion

\begin{tabular}{|c|c|c|c|}
\hline \multirow{2}{*}{ Variables } & \multicolumn{2}{c|}{ Perception of Emotion } \\
\cline { 2 - 4 } & Low & High \\
\hline \multirow{2}{*}{ Self-Esteem } & High & 2.160 & 2.203 \\
\cline { 2 - 4 } & Low & 0.022 & 0.354 \\
\hline
\end{tabular}




\section{DISCUSSIONS}

This study conducted by researcher as the discovery of knowledge about the emotional intelligence competencies, self-esteem and personality of employees. . Selection of employees as a source of this study is appropriate because there is interaction between the employee and the scenario at work. Extraversion personality is one of the variable that possible can have an impact on the relationship between emotional intelligence and employee self-esteem. The finding of the analysis has confirmed that the two research hypothesis is accepted when clearly show that there was a moderator effect on the relationship between perception and appraisal of emotion, and understanding emotions with self-esteem of the local authorities studied. This study produced to test the function of the employee's personality as a moderating factor on the relationship between emotional intelligence and self-esteem of employees in the workplace. Since many decades in the world of research, the study focused on the relationship and impact of emotional intelligence on organizational effectiveness, leadership, motivation and job satisfaction (Seyyed Hossein et al., 2012). However, it is less to focus on the influence of personality on the emotional intelligence and employee self-esteem. Through this study as well, the researchers tested the effect of the personality trait of extraversion as a moderator on the relationship between emotional intelligence in two dimensions of competence and self-esteem. The results of the analysis confirm that there are two hypotheses was accepted because it was found the first moderating effect of extraversion personality as moderator on the relationship between emotional intelligence (perception and appraisal of emotion) with self-esteem $\left(R^{2}=\right.$ .225, $\left.\Delta \mathrm{R}^{2}=.021, \mathrm{p}<.05\right)$.

The results clearly showed that extraversion can be set to function as a moderator when the relationship between perception and appraisal of emotion with a strong self-esteem had been exist when extraversion was at high level, compared with the low levels of extraversion that will cause the relationship of perception and appraisal of emotion with self-esteem is becoming weaker. Strengths and weaknesses in the relationship between both of these variables at the two local authorities is something that researchers can proved, when the personality trait of extraversion play a role in providing information on when and under what circumstances such relationships may occur. Extraversion which is more positive feature can assist employees to making the good of perception and appraisal of emotion. Through the high extraversion as well, employees are able to identify their emotions itself and the emotions of others, so that can help to increase positive self-esteem in themselves.

The results of the analysis also showed that the second moderating effect of extraversion personality on the relationship between emotional intelligence (perception and appraisal of emotion) with self-esteem $\left(R^{2}=\right.$ .231, $\left.\Delta \mathrm{R}^{2}=.035, \mathrm{p}<.05\right)$. Once again extraversion serve as moderator when the relationship between understanding emotion and self-esteem will be enhanced if extraversion were on a high level, compared with the low levels of extraversion for causing understanding emotions relationship with self-esteem among employees is becoming weaker. High extraversion among employees can help them to achieve the competence to understand their own feelings and emotions of others, so that also allows employees to achieve the high positive self-esteem. But employees will be difficult to understand their own feelings or anyone else if they have a low extraversion and that could affect their self-esteem. The findings of this study support the findings of Bao Chun (2012). Therefore, the findings of this research can also provide new clues for a different dependent variable compare with the study by Bao Chun (2012). This findings as well showed there is a significant positive correlation between extraversion with employees' self-esteem. It shows that extraversion trait not only has a relationship with emotional intelligence and self-esteem, but also shows it was function as a moderator between the two variables. These findings also support the findings of Abdullah et al. (1998).

\section{CONCLUSION}

This study concludes that in organizational psychology does not rely on the expertise and high intellect alone, but it is more on issues related to affective elements in man that should be established in advance in order to achieve the effectiveness of organizational behavior in workplace. It should be supported by the strength of the emotional intelligence competencies, which involve self-esteem, as well the good personality. Emotional intelligence also must be adapted to function needs to make them more positive and stable in their emotion, thereby making better quality work because it has a high self-esteem. Impact of extraversion personality on emotional intelligence among employee is a significant issue in managing their self-esteem when positive self-esteem can help them to always in a positive feeling, thinking and behavior. This study is certainly capable of inspiring new ideas that can lead to other research problem statement in the years to come, as well can help add to the literature review of other researchers. 


\section{ACKNOWLEDGMENT}

This research paper is made through the help and support from my parents, lecturers, family, and friends. Thanks a lot for the moral supporting.

This research paper was fully supported by Universiti Tun Hussein Onn Malaysia, through the Office for Research, Innovation, Commercialization and Consultancy Management (ORICC), and Registrar Office.

A very big thank you also to my colleagues from Universiti Tun Hussein Onn Malaysia who provided insight and expertise that greatly assisted the research.

I would like also to show my gratitude to my work place which is Universiti Tun Hussein Onn Malaysia, for giving me the chance to present and publish this paper in the international level. Come with the slogan 'with wisdom we explore', I feel proud to be academician in this place.

\section{REFERENCES LIST}

Abdul Kadir Othman (2010). The influence of emotional intelligence on front-line employees' job performance in service business. Thesis of Doctor of Philosophy Administrative Science and Policy Studies. Universiti Teknologi Mara.

Baron, R. M dan Kenny, D. A. (1986). The moderator-mediator variable distinction in social psychological research: conceptual, strategic, and statistical considerations. Journal of Personality and Social Psychology. 51(6) : 1173-1182.

Bao-Yiann \& Chun-Chi Yang (2012). The moderating of personality traits on emotional intelligence and conflict management styles. Psychological Reports; Jun 2012, Vol. 110, Issue 3, p.1021.

Bouvard, M., Aulard-Jaccod, J., Pessonneaux, S., Hautekeete, M. \& Roge, B. (2010). A study on the abbreviated form of the Eysenck Personality Questionnaire Revised-Abbreviated (EPQR-A) in a student population. L Encephale, 12/2010; 36(6),510-2. Doi: 10.1016/j.encep.2010.02.006.

Brian J. Ayotte, Guy G. Potter, Heather T. Williams, David C. Steffens \& Hayden B. Bosworth (2009). The moderating role of personality factors in the relationship between depression and neuropsychological functioning among older adults. Int J Geriatr Psychiatry, September 2009, 24(9): 1010-1019. Doi: $10.1002 / g p s .2213$.

Caruso, D.R., Mayer, J.D., \& Salovey, P. (2002). Relation of an ability measure of emotional intelligence to personality. Journal of Personality Assessment, 79, 306-320.

Ibrahim, F.W. \& Abd. Karim, M.Z. (2004). Efficiency of Local Governments in Malaysia and its Correlates. International Journal of Management Studies, vol.11(1), pp.57-70.

James, E. Tingstad (1994). Improving your staff's self-confidence. R\&D Innovator. Volume 3, Number 2.Article 79.

Korman, A.K. (1970). Toward a hypothesis of work behavior. Journal of Applied Psychology. 54, 31-41.

Korman, A.K. (1976). Hypothesis of work behavior revisited and an extension. Academy of Management Review. 1, 50-63.

Krejcie, R. V. \& Morgan, D. W. (1970). Determining Sample Size for Research Activities. Educational and Psychological Measurement. 30 : 607-610.

Lourdes Rey, Natalio Extremera \& Mario Pena (2011). Perceived emotional intelligence, self-esteem and life satisfaction in adolescents. Psychosocial Intervention, Vol. 20, pp. 227-234.

Maimunah Aminuddin (1992). Human Resource Management. Kuala Lumpur: Fajar Bakti.

Mayer, J. D., Caruso, D., \& Salovey, P. (1999). Emotional intelligence meets traditional standards for an intelligence. Intelligence. 27, pp.267-298.

McIntyre, L. J. (2005). Need To Know: Social Science Research Methods. New York: McGraw Hill.

Neustadt, Elizabeth; Chamorro-Premuzic, Tomas; Furnham, Adrian (2006). The relationship between personality traits, self-esteem, and attachment at work. Journal of Individual Differences. Vol 27(4), 2006, pp. 208-217. 
Othman Abdul Kadir, Daud Norzaidi Mohd, Kassim Raja Suzana Raja (2011). The moderating effect of neuroticism on the relationship between emotional intelligence and job performance. Australian Journal of Basic \& Applied Sciences; 2011, Vol. 5, Issue 6, p.801.

Sandeep Kumar \& Singh A.P. (2011). Personality as a moderator between stress state and job attitudes. Indian Journal of Social Science Researches, Vol. 8, No. 1-2, pp. 149-158.

Schutte, N. S., Malouff J. M., Simunek, M., Hollander, S., \& McKenley, J. (2002). characteristic emotional intelligence and emotional well-being. Cognition and Emotion. 16, 769-785.

Seyyed Hossein Mousavi, Saeed Yarmohammadi, Ayoub Bani Nosrat \& Zabiholah Tarasi (2012). The relationship between emotional intelligence and job satisfaction of physical education teachers. Annals of Biological Research, 3(1):736-745.

Tamkins, M. (2010). The relation of personality to organization-based self-esteem: an application of the fivefactor model of personality. Ph.D. dissertation, Columbia University, United States -- New York. Retrieved April 10, 2010, from Dissertations \& Theses: Full Text.(Publication No. AAT 3285180).

Tracey Lee Tafero (2007). Personality predictors of motivation to lead. Disertasi ljazah Doktor Falsafah. Graduate School of Clemson University.

Trayambak Tiwari, Anju L. Singh \& Indramani L. Singh (2009). The short-form revised Eysenck Personality Questionnaire: A Hindi edition (EPQRS-H). Industrial Psychiatry Journal, Jan-June 2009, Vol. 18, Issue 1, pp.27-31.

Zulnaidi, Y. (2008). A structural Relationship Between Total Quality Management, Strategic Control Systems and Performance of Malaysia Local Governments. Unpublished Ph.D. Dissertation: Universiti Utara Malaysia. 